\title{
1 Olfactory host entry supports herpesvirus recombination
}

2

\section{Authors}

4 Wanxiaojie Xie ${ }^{1}$, Kimberley Bruce ${ }^{1}$, Helen E. Farrell ${ }^{1,2}$, Philip G. Stevenson ${ }^{1,2 \#}$

5

\section{Affiliations}

$7{ }^{1}$ School of Chemistry and Molecular Biosciences, University of Queensland, Brisbane, Australia.

$8{ }^{2}$ Child Health Research Center, University of Queensland, South Brisbane, Australia.

9

10 \#Correspondence: Dr Philip Stevenson; School of Chemistry and Molecular Biosciences, University

11 of Queensland, St Lucia, 4072, Queensland, Australia; email: p.stevenson@uq.edu.au. 


\section{Abstract}

14 Herpesvirus genomes record abundant recombination. Its impact on infection remains ill-

15 defined. When co-infecting mice by the natural olfactory route, individually incapacitated Murid

16 Herpesvirus-4 (MuHV-4) mutants routinely recombined to restore normal host colonization. Lung

17 infection rescued much less well. Murine cytomegalovirus mutants deficient in salivary gland

18 colonization also showed rescue via the nose but not the lungs. As nose and lung infections show

19 similar spread, efficient recombination seemed specific to olfactory entry. Rescue of replication-

20 deficient MuHV-4 implied co-infection of the first encountered cells, and this worked also with

21 asynchronous inoculation, suggesting that latent virus could lie in wait for later reactivation. Inhaled

22 MuHV-4 is commonly caught on respiratory mucus, which epithelial cilia push back towards the

23 olfactory surface, and infection was correspondingly frequent at the anterior olfactory edge. Thus

24 olfactory entry provides a general means for herpesviruses to meet. 


\section{Author summary}

28 Inter-strain recombination allows viruses to optimise infection in diverse hosts. Many herpesviruses

29 show past recombination. Yet they are ancient pathogens, so this past may be remote and

30 recombination rare. Diverse herpesviruses enter new hosts via olfactory cells. We show that such

31 entry routinely allows recombination between co-infecting virus strains, even when one strain

32 cannot spread. Recombination was contrastingly rare after lung infection. Thus, entry via olfactory

33 cells specifically supports frequent herpesvirus recombination. 


\section{Introduction}

Outbred hosts subject viruses to serial changes in selection. Herpesviruses, with proof-

reading polymerases, are slow to make new mutations [1]. Nonetheless some human

cytomegalovirus (HCMV) and Herpes simplex virus type 1 (HSV-1) genes display marked diversity,

including disruption [2,3]. The latency genes of Epstein-Barr virus (EBV) also vary greatly [4]. Ancient

diversity plus present stability gives herpesvirus genes allelic forms, which interact with host alleles to influence infection outcomes. For example the murine cytomegalovirus m157 evolved to inhibit NK cells [5], but in Ly49H+ mice delivers instead disadvantageous activation [6, 7]. Herpesvirus strains often co-infect [2-4], and genome sequences show that co-infections must have met to make recombinants [8-11]. However each infection is dilute, and immunogenicity creates inter-strain competition. Longitudinal analysis has identified likely instances of HCMV recombination [12], but in immunodeficient hosts with high viral loads and susceptibility to reinfection. While EBV co-infection is common in infectious mononucleosis [13], that is 1-3 months after entering an immunocompetent host [14], serial strain typing has been limited to single loci.

50 Thus it is unclear whether divergent strains co-infect cells frequently enough to form functional gene

51 pools, or whether recombination rarely alters outcomes. Recombination seems most likely to result in early infection, when viral loads are largest.

53 Early human herpesvirus infections are hard to sample, so their routes and recombination

54 opportunities remain obscure. Experimental infections are more accessible. Yet most employ 55 invasive inoculations, via virus injection or aspiration under anaesthesia $[15,16]$, which may bypass 56 (or make) bottle-necks for recombination. The prominent presence of EBV in tonsils during infectious

57 mononucleosis led to assuming that $\gamma$-herpesviruses enter orally $[17,18]$. However EBV DNA appears 58 in blood before saliva [19], arguing that tonsillar infection is host exit, not entry. This result was 59 anticipated by analysis of the related Murid Herpesvirus-4 (MuHV-4), which found orally fed virions 
60 were non-infectious unless they reached the respiratory tract [20], and submucosal B cell

61 colonisation was subsequent to systemic spread [21]. MuHV-4 enters minimally manipulated mice

62 via the olfactory epithelium [22]. The only natural non-olfactory uptake known is genital [23].

63 Olfactory infection spreads to lymph nodes, via dendritic cells [24], then to the spleen and beyond

64 via B cells [25].

65 While olfactory entry remains unproven for EBV, it is evident for MCMV, including

66 spontaneous transmission [26], and for HSV-1 [27]. HCMV has an olfactory receptor [28]. MuHV-4,

67 MCMV and HSV-1 diverged hundreds of millions of years ago [29], so their shared olfactory entry

68 suggests that many mammalian herpesviruses use the same route. We tested with MuHV-4 whether

69 it offers an opportunity for co-infecting viruses to recombine. 


\section{Results}

\section{Nasal infection with latency-deficient MuHV-4 mutants}

$\gamma$-herpesviruses colonize their hosts lytically and by latency-associated lymphoproliferation.

MuHV-4 mutants lacking stable latency have been made by over-expressing the ORF50 viral transactivator [30, 31], or by disrupting ORF73 episome maintenance [32, 33]. M50 MuHV-4 has an MCMV IE1 promoter fragment inserted in the $5^{\prime}$ untranslated region of ORF50, deregulating its transcription [30]. ORF73FS MuHV-4 has a frameshift mutation in ORF73 [32] (Fig.1a). Both mutants replicate lytically in the lungs after a $30 \mu$ inoculation under anaesthesia, but poorly colonize lymphoid tissue. Nasal inoculation ( $5 \mu$ l without anaesthesia) similarly led to local lytic spread but signficantly less lymph node infection than wildtype, with none detectable in spleens at day 18

81 (Fig.1b).

\section{Recombinational rescue of latency-deficient mutants after nasal co-infection}

To test rescue by recombination, we co-infected mice nasally with ORF73FS and M50 MuHV-

4, then 25 days later determined latency by infectious centre assay (Fig.2). 11/12 co-infected mice showed significant splenomegaly (Fig.2a) and splenic infection (Fig.2b). No singly infected mice did so - the M50 [30] and ORF73FS mutations [32, 34] have consistently not shown spontaneous reversion. Co-infection alone might complement ORF73 deficiency, but ORF50 over-production should have a dominant detrimental impact on latency. Therefore recombinational rescue seemed more likely. This was confirmed by PCR analysis of viruses cloned from splenic infectious centres.

91 Clones from 4/4 co-infected mice showed M50 and ORF73 PCR products of wild-type size (Fig.2c, 2d), and their DNA sequences exactly matched wild-type. unsurprising: even cells co-infected with MuHV-4 in vitro yield only a few percent recombinants 
95 (PGS, unpublished data), so they would inevitably initiate at low dose. After 3 months, the splenic

Linear genomes can repair single mutations by one recombination. Herpesvirus genome ends vary more than their middles, and one recombination would allow co-infecting viruses to exchange left or right end ends. However in more detail, the genome core comprises conserved blocks, between which lie more varied loci. To exchange these while retaining left and right ends would require two recombinations. To simulate this setting, we co-infected mice with M50 MuHV-4 and an ORF73FS mutant that also lacked $10 \mathrm{~kb}$ from its left end (ORF73FS $\Delta \mathrm{L}$ ) [37] (Fig.1a). The $\Delta \mathrm{L}$ mutation deletes ORFs M1-M4, and independently impairs the establishment of a normal latent load [38]. Nasal co-infection nonetheless gave rescue (Fig.3), implying recombination both between ORFs 50 and 73, and between ORF50 and $\Delta \mathrm{L}$ (see Fig.1a). Thus there was no barrier to more complex categories of recombinational rescue.

\section{Lung co-infection with latency-deficient MuHV-4 mutants}

To determine whether MuHV-4 co-infection generally provides genetic rescue, or whether this a particular property of olfactory entry, we tested lung inoculation, a widely used immunological model. We gave mice M50 and ORF73FS MuHV-4 as before but in $30 \mu l$ under anaesthesia. As alert mice retain little free fluid in their upper airways [39], lung inoculation is more efficient than nasal. Therefore we gave $10^{4}$ rather than $10^{5}$ p.f.u. of virus. We assayed spleens for latent load 17 days later (Fig.4a) - as lung infection is more extensive than olfactory, it drives faster down-stream spread [20]. Low levels of latent infection were seen in the spleens of 3/6 mice. 
bioRxiv preprint doi: https://doi.org/10.1101/2020.08.24.264903; this version posted August 24, 2020. The copyright holder for this preprint (which was not certified by peer review) is the author/funder, who has granted bioRxiv a license to display the preprint in perpetuity. It is made available under aCC-BY 4.0 International license.

number of mice with detectable latent infection and in their titers. However direct comparison is difficult between mice infected by different routes. Also, while nasal infection does not reach the lungs, lung inocula must navigate the nose, so the low level splenic latency seen in Fig.4a might have come from contaminating olfactory infection. To address these points we assayed separately the superficial cervical (SCLN) and mediastinal lymph nodes (MLN) of co-infected mice, for latent virus after 12 days (Fig.4b). While lung and olfactory infections both spread via lymph nodes, the SCLN drain the nose whereas the MLN drain the lungs. Mononucleosis-associated systemic viral spread reaches far lymph nodes, but early infections reflect primary replication in peripheral sites. Specifically, low dose day 12 olfactory infections spare the MLN, so infection routes can be distinguished. At this time 4/7 mice had a low level of SCLN latency, and 1/7 mice had MLN latency. Wild-type controls showed significantly more MLN than SCLN infection, matching the more extensive lytic infection of lungs; and the sole positive MLN of the co-infected cohort had a correspondingly higher titer than any SCLN. Thus, we could be confident of not missing recombinational rescue in the lungs. It seemed likely that the low-level day 17 spleen infections in Fig.4a resulted from virus caught inadvertently in the upper respiratory tract, while lung co-inocula rarely recombined: $1 / 7$ mice, versus $11 / 12$ for deliberate olfactory infection in Fig. $2 b(p<0.002)$. To explore whether recombinational rescue was specific to MuHV-4, we tested MCMV, coinfecting BALB/c mice with mutants lacking M33 or M78 (Fig.5). MCMV needs both these G proteincoupled receptor homologues to successfully colonize the salivary glands [39, 40]. Salivary gland plaque assays at 18 days post-lung inoculation were positive only for the wild-type control (Fig.5a).

144 However at day 18 after nasal co-infection, salivary glands were positive for all co-infected mice, and

145 for no M33- or M78- single controls (Fig.5b). 
bioRxiv preprint doi: https://doi.org/10.1101/2020.08.24.264903; this version posted August 24, 2020. The copyright holder for this preprint (which was not certified by peer review) is the author/funder, who has granted bioRxiv a license to display the preprint in perpetuity. It is made available under aCC-BY 4.0 International license.

Viruses cloned from the salivary glands of $4 / 4$ nasally co-infected mice showed a wild-type

147 M33 locus by PCR (Fig.5c). One clone retained a mutant M78 locus (Fig.5d), perhaps because M78deficient viruses do not always completely lack salivary gland infection [41, 42]. Nonetheless recombination was evidently the main route of rescue. Overall, MCMV like MuHV-4 showed recombinatorial rescue after olfactory infection but not after lung infection.

\section{Recombination occurs early in olfactory infection} recirculation $[40,43]$. Thus inefficient recombination via the lungs argued that it occurred early in MuHV-4 in SCLN at 8 days after nasal M50 / ORF73FS co-infection than after single infections (Fig.6a). The wide spread of co-infection titers at this early timepoint made its yield not significantly more than M50 alone. Therefore we looked further for evidence of recombination by inoculating virus clones from SCLN into the lungs of naive mice (Fig.6b). At day 14, clones recovered from M50 or ORF73FS single inoculations yielded no infectious centres, while all bar one of those from mixed inoculations - presumably a parental M50 virus - had titers indistinguishable from wild-type. Therefore olfactory MuHV-4 recombined before leaving lymph nodes.

We recovered no recombinant viruses from co-infected noses. This likely reflected that without the selective pressure of having to establish latency, the proportion of recombinants remained low; and as M50 MuHV-4 out-replicates the wild-type in vitro [29], it predominated when producing stocks from a mixed population. Therefore to position more precisely the place of recombination, we co-infected mice with ORF73FS and ORF50DEL MuHV-4 (Fig.6c). The latter mutant lacks all lytic replication, due to a large deletion in ORF50 (Fig.1a). In vitro it must be propagated in complementing $\mathrm{ORF} 50^{+}$cells [20]; in vivo it cannot spread further than the first

171 encountered cells [25]. Nonetheless, spleens and SCLN at 18 days after nasal co-infection yielded 
172 recoverable virus for $3 / 3$ mice, and spleens at after 25 days did so for $5 / 5$ mice. Therefore co-

173 infection must have occurred in the initially infected cells. ORF73FS MuHV-4 could in principle complement ORF50DEL in trans, but an ongoing need for co-infection would render this less efficient than recombination, and viruses cloned from day 25 spleens of 4/4 co-infected mice showed wildtype ORF50 and ORF73 loci by PCR (Fig.6d, 6e). DNA sequencing confirmed identity with the wildtype.

\section{Recombination does not require simultaneous co-infection} neurons and sustentacular cells [22]. We reasoned that it might remain accessible to recombination with a super-infecting virus, and tested this by infecting mice nasally with ORF50DEL MuHV-4, then 5 days later giving the same mice nasal ORF73FS MuHV-4 (Fig.7). We assayed spleens for recoverable virus another 18 days later. 5/6 co-infected mice showed splenic infection, while no singly infected controls did so. Therefore latent infection supplied a sufficient substrate for subsequent olfactory rescue.

A possible site of olfactory recombination. should reduce recombination. However the distribution of early olfactory infection is not uniform. A conspicuously common site is the respiratory / olfactory epithelial border (Fig.8). Anatomical complexity [44] makes this border hard to check completely, but retrospective review identified its involvement in 23/30 early infections (1-3 days post-inoculation). Generally noses were examined only until at 50-100 infected cells were found, so involvement of the border was likely underestimated. Frequent infection initiation here would explain the recombinatorial rescue of replication-deficient virus. 


\section{Discussion}

Herpesviruses interact with polymorphic host genes, and so encounter environmental change in each infection. Unlinking viral genes can generate new combinations to cope. Host genes mix in meiosis; viruses must count on co-infecting cells. While herpesviruses show historic recombination, whether this is occasional and mostly old, or whether viral genes reassort routinely has been obscure. We showed that for both MCMV and MuHV-4, recombination after olfactory entry routinely rescues replication defects. It provided repair where point mutations did not, and was efficient enough to overcome immune priming by the parent viruses. and surface tension likely captures them onto mucus. Consistent with this concept, inhaled virions appear immediately on the respiratory epithelium then disappear from here, while on the olfactory epithelium they accumulate and infect [22]. Respiratory epithelial cells are not infected because they

212 lack apical heparan. Instead their cilial beating bears mucus-bound virions backwards. Hence infection commonly occurred close to the respiratory / olfactory border. Such concentration of captured virions should promote co-infection. It is probably more pronounced still in natural transmission, as negligible volume would then minimize nasal fluid flow. Cilial clearance of captured virions would explain further why olfactory infections fail to involve the lungs $[20,26,27]$, as bronchial cilial push their mucus upwards to be swallowed. sustentacular cells, which accumulate virions on their apical microvilli [22]. The neuronal cilia are 220 too fine to transport virions internally, so retrograde cilial transport may move bound virions 
222 rescue via the lungs was rare, despite more lytic replication happening here. MuHV-4 lung entry

223 involves macrophages capturing virions from alveolar epithelial cells [45], reminiscent of

224

sustentacular cells capturing them from olfactory cilia. However inoculated virions are diluted among many more alveoli $[45,46]$. Thus there may be little co-capture, and whether infection can spread between alveoli is far from clear.

Limited rescue via the lungs argued against frequent recombination down-stream of the olfactory epithelium, as subsequent spread seems similar between these routes - via dendritic cells to B cells. Once a tissue barrier is breached immunity begins, so infection must spread fast, implying selection for divergence over convergence. Down-stream dilution would explain how recombinants escaped the dominant negative impact of M50 on latency. While the latency defects of M50 and ORF73FS MuHV-4 made recombination in spleens impossible to assay, spread here recapitulates the myeloid / lymphoid virus relay into SCLN [24], via reactivation from B cells [47] then virion capture and transfer by marginal zone macrophages [25]. Thus it provides no obvious point of convergence. Ultimately, many reactivations pool progeny virions in saliva, but recombination requires that these virions co-infect. The obvious site for this is in new hosts.

EBV carriers can co-shed virus strains acutely [48], but long term infections seem to select single dominant strains [49]. So if co-infection depended completely on carriers co-shedding - if it takes a co-infection to make a co-infection - how could could it remain common? There must also be a means to mix serially infecting viruses. MuHV- 4 vaccine assays argue that anti-viral immunity inhibits super-infection [46], even if the immunizing virus persists poorly $[35,36]$. However establishing effective immunity takes time. The antibody response to MuHV-4 does not reach its peak for at least 3 months [50]; EBNA-specific antibodies appear may months after EBV acquisition, indicating immunity is still maturing; and EBV loads remain elevated for at least as long [51]. Thus an infant infected by a single maternal strain could acquire more from other carers [52] while still susceptible to super-infection. 
248 nose means infected hosts inevitably inhale some of their own shed salivary virus. So carriers may

249 continue to display their resident viruses for recombination. Latency in olfactory epithelial cells

250 provides another means to meet. Olfactory entry by herpesviruses depends on heparan binding [22].

251 As such binding is widely shared, other viruses might also meet at the respiratory / olfactory border.

252 The inherent dilution of transmission presents a problem for adeno-associated virus, to find an

253 assisting adenovirus in each new host; but as both bind heparan [53, 54], adeno-associated virus

254 could use latency in the olfactory epithelium to ambush its essential aide. 


\section{Materials and Methods}

257 Mice C57BL/6 or BALB/c mice were infected intransally (i.n.) when 6-14 weeks old, either in 30 $\mu$ l under isoflurane anaesthesia to reach the lungs ( $10^{4}$ p.f.u.), or in $5 \mu l$ without anaesthesia ( $10^{5}$ p.f.u.), to infect only the upper respiratory tract. A higher dose was used for upper respiratory tract infection, as most of the inoculum is swallowed [39]. Statistical comparison was by Student's 2-tailed unpaired $t$-test unless stated otherwise.

Committee in accordance with the Australian code for the care and use of animals for scientific purposes, from the Australian National Health and Medical Research Council (projects 391/15, $479 / 15,196 / 18,207 / 18)$ cells (ATCC CRL-1658) and NIH-3T3-ORF50 cells [20] were grown in Dulbecco's modified Eagle's medium (Gibco) with $2 \mathrm{mM}$ glutamine, $100 \mathrm{IU} / \mathrm{ml}$ penicillin, $100 \mu \mathrm{g} / \mathrm{ml}$ streptomycin and $10 \%$ fetal calf serum (complete medium). Murine embryonic fibroblasts were grown in similarly supplemented minimal essential medium. MuHV-4 with a frameshift inactivating ORF73 [32], with an additional deletion of $10 \mathrm{~kb}$ from the genome left end, that includes ORFs M1, M2, M3, M4 and 4 [37], with a

274 deletion of ORF50 exon 2 [20], or with an MCMV IE1 promoter fragment inserted in the $5^{\prime}$ untranslated region of ORF50 [30] are described. ORF50DEL MuHV-4 was grown and titered in NIH-

276 3T3-ORF50 cells. Other MuHV-4 derivatives were grown and titered in BHK-21 cells. MCMV mutants

277 with a $\beta$-galactosidase expression cassette disrupting M33 [40] or M78 [41] were derived from K181 278 strain Perth, which was used as the wild-type. All were grown in NIH-3T3 cells. Infected cell 
supernatants were cleared of debris by low speed centrifugation ( $200 \times \mathrm{g}, 5 \mathrm{~min})$. Cell-free virions

280

281

282

283

285
Infectious virus was quantified by plaque assay. For MuHV-4 [55], virus stocks or freeze-thawed tissue homogenates dilutions were incubated with BHK-21 cells $\left(2 \mathrm{~h}, 37^{\circ} \mathrm{C}\right)$, overlaid with complete medium / $0.3 \%$ carboxymethylcellulose, cultured for 4 days, fixed with $1 \%$ formaldehyde and stained with $0.1 \%$ toluidine blue for plaque counting. MCMV was titered similarly but on murine embryonic fibroblast monolayers [41], and was adhered by centrifugation (500 $\times \mathrm{g}$, $30 \mathrm{~min}$ ) before discarding the inoculum. Total recoverable MuHV-4 (latent plus pre-formed infectious virus) was quantified by infectious centre (i.c.) assay [55]. Freshly isolated lymph node or spleen cells were layered onto BHK-21 cell monolayers then cultured and processed as for plaque assays. For parallel assays of pre-formed infectious virus, samples were first frozen and thawed.

\section{Viral Genome Quantitation}

MuHV-4 genomic coordinates 4163-4308 (M2 ORF; primers

DNA (Nucleospin Tissue kit, Macherey-Nagel). PCR products quantified with Sybr green (Thermo Fisher Scientific) were compared to a standard curve of cloned template amplified in parallel, and distinguished from paired primers by melting-curve analysis. Correct sizing was confirmed by electrophoresis and ethidium bromide staining. Cellular DNA in the same samples was quantified by parallel amplification of a $\beta$-actin gene fragment.

\section{Virus genotyping}

M50 MuHV-4 has the proximal 416bp of the murine cytomegalovirus IE1/IE3 promoter inserted at genomic coordinate 66718, between the ORF50 transcription (66642) and translation start sites (66760). To detect this insert we amplified across genomic coordinates 66580-66848, using primers 5'-cacattatcccacaatgtgctgc and 5'-gaaatactgatctgtctgcgtgg. This gave a 268bp wild-type product and a 684bp M50 product. ORF50DEL MuHV-4 has genomic coordinates 
bioRxiv preprint doi: https://doi.org/10.1101/2020.08.24.264903; this version posted August 24, 2020. The copyright holder for this preprint (which was not certified by peer review) is the author/funder, who has granted bioRxiv a license to display the preprint in perpetuity. It is made available under aCC-BY 4.0 International license.

305

306

307
Organs were fixed in $1 \%$ formaldehyde / $10 \mathrm{mM}$ sodium

\section{Immunostaining tissue sections} periodate / $75 \mathrm{mM}$ L-lysine $\left(18 \mathrm{~h}, 4^{\circ} \mathrm{C}\right)$. Noses were then decalcified in $150 \mathrm{mM} \mathrm{NaCl} / 50 \mathrm{mM}$ TrisCl $\mathrm{pH} 7.2$ / $270 \mathrm{mM}$ EDTA for two weeks at $23^{\circ} \mathrm{C}$, changing the solution every 3 days, then washed twice in PBS. Samples were dehydrated in graded ethanol solutions, embedded in paraffin, and cut with a microtome. Sections were then de-waxed in xylene, rehydrated, washed $3 x$ in PBS and air-dried. Endogenous peroxidase activity was quenched in $\mathrm{PBS} / 3 \% \mathrm{H}_{2} \mathrm{O}_{2}$ for $10 \mathrm{~min}$. Sections were blocked $\left(1 \mathrm{~h}, 23^{\circ} \mathrm{C}\right)$ with $0.3 \%$ Triton $\mathrm{X}-100 / 5 \%$ normal donkey serum, and incubated $\left(18 \mathrm{~h}, 4^{\circ} \mathrm{C}\right)$ with antiMuHV-4 rabbit pAb, which recognizes a range of virion proteins by immunoblot, including the products of ORF4 (gp70), M7 (gp150), and ORF65 (p20) [55]. Sections were additionally blocked with Avidin/Biotin Blocking Kit (Vector Laboratories). Detection was with biotinylated goat anti-rabbit IgG 

made available under aCC-BY 4.0 International license.

331 pAb $\left(1 \mathrm{~h}, 23^{\circ} \mathrm{C}\right.$, Vector Laboratories), Vectastain Elite $A B C$ Peroxidase system, and ImmPACT

332 diaminobenzidine substrate (Vector Laboratories). Stained sections were counterstained with

333 Mayer's Hemalum (Merck), dehydrated and mounted in DPX (BDH). 
bioRxiv preprint doi: https://doi.org/10.1101/2020.08.24.264903; this version posted August 24, 2020. The copyright holder for this preprint (which was not certified by peer review) is the author/funder, who has granted bioRxiv a license to display the preprint in perpetuity. It is made available under aCC-BY 4.0 International license.

Financial disclosure statement

336 The work was supported by grants from the National Health and Medical Research Council (project

337 grants 1122070, 1140169), the Australian Research Council (grant DP190101851), and Queensland

338 Health.

339 


\section{References}

342 1. Szpara ML, Gatherer D, Ochoa A, Greenbaum B, Dolan A, Bowden RJ, et al. Evolution and

343 diversity in human herpes simplex virus genomes. J Virol. 2014;88: 1209-1227.

$3442 . \quad$ Suárez NM, Wilkie GS, Hage E, Camiolo S, Holton M, Hughes J, et al. Human Cytomegalovirus

345 Genomes Sequenced Directly From Clinical Material: Variation, Multiple-Strain Infection,

346 Recombination, and Gene Loss. J Infect Dis. 2019;220: 781-791.

347 3. Palser AL, Grayson NE, White RE, Corton C, Correia S, Ba Abdullah MM, et al. Genome 348 diversity of Epstein-Barr virus from multiple tumor types and normal infection. J Virol. 2015;89:

$349 \quad 5222-5237$

350 4. Abbotts J, Nishiyama Y, Yoshida S, Loeb LA. On the fidelity of DNA replication: herpes

351 DNA polymerase and its associated exonuclease. Nucleic Acids Res. 1987;15: 1185-1198.

352 5. Pyzik M, Dumaine A, Charbonneau B, Fodil-Cornu N, Jonjic S, Vidal SM. Viral MHC class I-like

353 molecule allows evasion of NK cell effector responses in vivo. J Immunol. 2014;193: 6061-6069.

354 6. Smith HR, Heusel JW, Mehta IK, Kim S, Dorner BG, Naidenko OV, et al. Recognition of a virus-

355 encoded ligand by a natural killer cell activation receptor. Proc Natl Acad Sci USA. 2002;99: 8826-

3568831.

357 7. Corbett AJ, Coudert JD, Forbes CA, Scalzo AA. Functional consequences of natural sequence 358 variation of murine cytomegalovirus m157 for Ly49 receptor specificity and NK cell activation. J

359 Immunol. 2011;186: 1713-1722.

360 8. Pfaff F, Groth M, Sauerbrei A, Zell R. Genotyping of herpes simplex virus type 1 by whole-

361 genome sequencing. J Gen Virol. 2016;97: 2732-2741.

362 9. Cudini J, Roy S, Houldcroft CJ, Bryant JM, Depledge DP, Tutill H, et al.

363 Human cytomegalovirus haplotype reconstruction reveals high diversity due to superinfection and 364 evidence of within-host recombination. Proc Natl Acad Sci USA. 2019;116: 5693-5698. 
365 10. McGeoch DJ, Gatherer D. Lineage structures in the genome sequences of three Epstein-

366 Barr virus strains. Virology. 2007;359: 1-5.

367 11. Kakoola DN, Sheldon J, Byabazaire N, Bowden RJ, Katongole-Mbidde E, Schulz TF, et al.

368 Recombination in human herpesvirus-8 strains from Uganda and evolution of the K15 gene. J Gen

369 Virol. 2001;82: 2393-2404.

12. Hage E, Wilkie GS, Linnenweber-Held S, Dhingra A, Suárez NM, Schmidt JJ, et al.

371 Characterization of Human Cytomegalovirus Genome Diversity in Immunocompromised Hosts by

372 Whole-Genome Sequencing Directly From Clinical Specimens. J Infect Dis. 2017;215: 1673-1683.

373 13. Sitki-Green D, Covington M, Raab-Traub N. Compartmentalization and transmission of 374 multiple Epstein-Barr virus strains in asymptomatic carriers. J Virol. 2003;77: 1840-1847.

375 14. Hoagland RJ. The incubation period of infectious mononucleosis. Am J Public Health Nations

376 Health. 1964;54: 1699-1705.

377 15. Gillet L, Frederico B, Stevenson PG. Host entry by $\mathrm{Y}$-herpesviruses-lessons from animal 378 viruses? Curr Opin Virol. 2015;15: 34-40.

379 16. Farrell HE, Stevenson PG. Cytomegalovirus host entry and spread. J Gen Virol. 2019 ;100: 545-553.

381 17. Hoagland RJ. The transmission of infectious mononucleosis. Am J Med Sci. 1955;229: 262-

382272.

383 18. Rickinson $A B$, Yao QY, Wallace LE. Epstein-Barr virus as a model of virus-host interactions. $B r$ 384 Med Bull. 1985;41: 75-79.

385 19. Dunmire SK, Grimm JM, Schmeling DO, Balfour HH, Hogquist KA. The Incubation Period of 386 Primary Epstein-Barr Virus Infection: Viral Dynamics and Immunologic Events. PLoS Pathog. 2015;11: 387 e1005286. herpesvirus-4 infection. J Gen Virol. 2009;90: 21-32. 
21. Frederico B, Milho R, May JS, Gillet L, Stevenson PG. Myeloid infection links epithelial and B

391

23. François S, Vidick S, Sarlet M, Desmecht D, Drion P, Stevenson PG, et al. Illumination of murine gammaherpesvirus-68 cycle reveals a sexual transmission route from females to males in laboratory mice. PLoS Pathog. 2013;9: e1003292.

24. Gaspar M, May JS, Sukla S, Frederico B, Gill MB, Smith CM, et al. Murid herpesvirus-4 exploits dendritic cells to infect B cells. PLoS Pathog. 2011;7: e1002346.

25. Frederico B, Chao B, May JS, Belz GT, Stevenson PG. A murid $y$-herpesviruses exploits normal splenic immune communication routes for systemic spread. Cell Host Microbe. 2014;15: 457-470.

26. Farrell HE, Lawler C, Tan CS, MacDonald K, Bruce K, Mach M, et al. Murine Cytomegalovirus Exploits Olfaction To Enter New Hosts. mBio. 2016;7: e00251-16.

27. Shivkumar M, Milho R, May JS, Nicoll MP, Efstathiou S, Stevenson PG. Herpes simplex virus 1 targets the murine olfactory neuroepithelium for host entry. J Virol. 2013;87: 10477-10488.

28. E X, Meraner P, Lu P, Perreira JM, Aker AM, McDougall WM, et al. OR14I1 is a receptor for the human cytomegalovirus pentameric complex and defines viral epithelial cell tropism. Proc Natl Acad Sci USA. 2019;116: 7043-7052.

29. McGeoch DJ, Rixon FJ, Davison AJ. Topics in herpesvirus genomics and evolution. Virus Res. 2006;117: 90-104.

30. May JS, Coleman HM, Smillie B, Efstathiou S, Stevenson PG. Forced lytic replication impairs host colonization by a latency-deficient mutant of murine gammaherpesvirus-68. J Gen Virol. 2004;85: 137-146.

31. Rickabaugh TM, Brown HJ, Martinez-Guzman D, Wu TT, Tong L, Yu F, et al. Generation of a latency-deficient gammaherpesvirus that is protective against secondary infection. J Virol. 2004;78: 9215-9223. 
32. Fowler P, Marques S, Simas JP, Efstathiou S. ORF73 of murine herpesvirus- 68 is critical for the

417 establishment and maintenance of latency. J Gen Virol. 2003;84: 3405-3416.

33. Moorman NJ, Willer DO, Speck SH. The gammaherpesvirus 68 latency-associated nuclear antigen homolog is critical for the establishment of splenic latency. J Virol. 2003;77: 10295-10303.

34. Lawler C, Stevenson PG. Limited protection against $\boldsymbol{y}$-herpesvirus infection by replicationdeficient virus particles. J Gen Virol. 2020;101: 420-425. gammaherpesvirus-68 latency by a latency-deficient mutant. J Gen Virol. 2004;85: 131-135. for ORF73. J Gen Virol. 2004;85: 609-613.

37. Lawler C, Simas JP, Stevenson PG. Vaccine protection against murid herpesvirus-4 is maintained when the priming virus lacks known latency genes. Immunol Cell Biol. 2020; 98:67-78. mutant of murine gammaherpesvirus 68 reveals tissue-specific genetic requirements for latency. J Virol. 2002;76: 6532-6544.

39. Tan CS, Frederico B, Stevenson PG. Herpesvirus delivery to the murine respiratory tract. J

432 Virol Methods. 2014;206: 105-114.

433 40. Farrell HE, Bruce K, Lawler C, Oliveira M, Cardin R, Davis-Poynter N, et al. Murine 434 Cytomegalovirus Spreads by Dendritic Cell Recirculation. mBio. 2017;8: e01264-17.

435 41. Yunis J, Farrell HE, Bruce K, Lawler C, Sidenius S, Wyer O, et al. Murine cytomegalovirus degrades MHC class II to colonize the salivary glands. PLoS Pathog. 2018;14: e1006905.

437 42. Davis-Poynter N, Yunis J, Farrell HE. The Cytoplasmic C-Tail of the Mouse Cytomegalovirus 7 Transmembrane Receptor Homologue, M78, Regulates Endocytosis of the Receptor and Modulates 439 Virus Replication in Different Cell Types. PLoS One. 2016;11: e0165066. 
44. Barrios AW, Núñez G, Sánchez Quinteiro P, Salazar I. Anatomy, histochemistry, and

443 


\section{Figure Legends}

\section{Figure 1. Nasal infection by MuHV-4 mutants lacking normal latency.}

a. A schematic sketch of MuHV-4 mutations shows the linear genome flanked by terminal repeats

472 (TR), with expanded views below. Replication-deficient ORF50DEL MuHV-4 has most of ORF50 exon

2 replaced by luciferase plus a polyadenylation site. ORF73FS MuHV-4 has a frameshift in ORF73,

which encodes the viral episome maintenance protein. The $\Delta \mathrm{L}$ virus mutation additionally deletes

$11 \mathrm{~kb}$ from the genome left end, removing ORFs M1-M4. M50 MuHV-4 has an MCMV IE1 promoter inserted in the 5' untranslated region of ORF50. p1-p6 show the locations of primers used to identify the ORF50DEL, M50 and ORF73FS mutations.

b. $\mathrm{C} 57 \mathrm{BL} / 6$ mice were infected nasally $\left(10^{5}\right.$ p.f.u. in $5 \mu \mathrm{l}$ without anaesthesia) with wild-type, M50 or spleens were titered by infectious centre assay. Symbols show individual mice, bars show means.

481 The dashed line shows the detection limit. Significant differences in virus recovery relative to wildtype are shown.

Figure 2. Recovery of latency after nasal co-infection with latency-deficient MuHV-4 mutants.

a. C57BL/6 mice were infected nasally ( $10^{5}$ p.f.u.) with wild-type, M50 or ORF73FS virus, or a 1:1 M50 / ORF73FS mix. Weigts of spleens 25 days later are shown, compared to naive mice, with significant splenomegaly for the wild-type and mixed infections. Symbols show individual mice, bars show means.

b. The spleens in a were titered for latent virus by infectious centre assay. Symbols show individuals, bars show means. The dashed line shows the lower limit of assay detection. Mixed M50 / ORF73FS

491 infection yielded significantly more virus than either single infection. No preformed infectious virus was recovered by parallel titer of freeze-thawed spleen samples. 
c. Viruses cloned (c1-c4) from spleens of mixed infection mice were genotyped by PCR across the M50 insertion site (primers $\mathrm{p} 1$ and $\mathrm{p} 2$ in Fig.1a). PCR products were resolved by agarose gel electrophoresis and stained with ethidium-bromide. WT and M50 are wild-type and M50 input viruses. $\mathrm{Mw}=$ molecular weight markers. Sequencing of the main (268bp) product of cloned virus DNA confirmed identity with the wild-type.

d. DNA from the cloned viruses in c was genotyped by PCR across the ORF73 frameshift (primers p5 and p6 in Fig.1a). PCR products were digested or not with BstEll, resolved by agarose gel electrophoresis, and stained with ethidium-bromide. WT and 73 are wild-type and ORF73FS input viruses. As the viruses were cloned prior to analysis, we interpret the minor residual $0.43 \mathrm{~kb}$ product for BstEll-digested c3 DNA as incomplete digestion. DNA sequencing of the main (428bp) undigested product of the cloned viruses confirmed identity with the wild-type.

e. $\mathrm{C} 57 \mathrm{BL} / 6$ mice were infected as in a. 3 months later, latent virus was detected by infectious centre assay. M50 / ORF73FS co-infection yielded significantly more virus than either single infection, and was indistinguishable from wild-type. Symbols show individual mice, bars show means. The dashed line shows the detection limit.

f. The spleens in e were assayed for viral genomes by quantitative PCR of extracted DNA. Viral copies are expressed relative to cellular $\beta$-actin copies amplified in parallel. M50 / ORF73FS co-infection yielded significantly more viral genomes than either single infection, and was indistinguishable from wild-type.

513 Figure 3. Recovery of latency after co-infection by M50 and ORF73FS $\Delta$ L mutants.

514 C57BL/6 mice were infected nasally ( $10^{5}$ p.f.u.) with wild-type, M50 or ORF73FS $\Delta$ L virus, or a 1:1

$515 \mathrm{M} 50$ / ORF73FS $\Delta \mathrm{L}$ mix. We also infected mice with a control $\Delta \mathrm{L}$ single mutant. Spleens were 516 infectious centre-assayed for latent infection 25 days later. Symbols show individual mice, bars show 517 means. The dashed line shows the detection limit. M50 / ORF73FS $\Delta \mathrm{L}$ co-infection yielded 
518 significantly more latency than either virus alone. No preformed infectious virus was recovered by

519 parallel titer of freeze-thawed spleen samples.

Figure 4. Little evidence of MuHV-4 recombination after lung co-infection.

522

a. C57BL/ 6 mice were infected in the lungs ( $10^{4}$ p.f.u. in $30 \mu$ under anaesthesia) with wild-type, M50 or ORF73FS viruses, or a 1:1 M50 / ORF73FS mix. Spleens were infectious centre assayed for latent virus 17 days later. Symbols show individual mice, bars show means. The dashed line is the detection

525 limit.

b. Mice were infected as in a. 12 days later, SCLN and MLN were infectious centre-assayed for latent

527 virus.

529 Figure 5. Rescue of MCMV mutants after co-infection in the nose but not the lungs.

530 a. BALB/c mice were infected in the lungs ( $10^{4}$ p.f.u.) with wild-type, M33- or M78- MCMV, or a 1:1

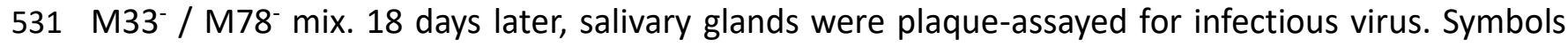
532 show individual mice, bars show means. The dashed line is the detection limit. Only wild-type 533 infection yielded recoverable virus.

b. BALB/c mice were infected nasally ( $10^{5}$ p.f.u.) with M33- or M78- MCMV, or a 1:1 M33- / M78- mix.

53518 days later, salivary glands were plaque-assayed for infectious virus. Symbols show individual mice,

536 bars show means. Only the mixed infection yielded recoverable virus.

537 c. DNA of virused cloned from mixed infection salivary glands in $\mathbf{b}$ was checked for M33 mutation by

538 PCR. 33 and 78 are the M33- and M78 input viruses. The predicted wild-type band is $572 \mathrm{bp}$. The

539 upper 33 sample band corresponds to the expected size for the lacZ cassette insertion of the mutant

$540(4.4 \mathrm{~kb})$. The source of the lower $(2.2 \mathrm{~kb}) 33$ sample band is unclear, but the 33 sample is clearly free

541 of wild-type DNA, and no recovered clone shows a mutant M33 locus.

543 virus. The other 3 clones had a wild-type M78 locus, indicating recombination. 
Figure 6. Early recombinational rescue of MuHV-4 after nasal co-infection.

a. C57BL/6 mice were infected nasally ( $10^{5}$ p.f.u.) with wild-type, M50 or ORF73FS MuHV-4, or a 1:1

M50 / ORF73FS mix. 8 days later, latent virus in SCLN was infectious centre-assayed. Symbols show individual mice, bars show means. The dashed line is the detection limit. Mixed infections gave higher titers than either component single infection, although the wide spread meant that as a group they were not significantly higher than M50 alone.

b. Viruses cloned from SCLN for each mouse in a were given i.n. to naive mice under anaesthesia to inoculate the lungs $\left(10^{3}\right.$ p.f.u. in $\left.30 \mu l\right)$. One clone from each positive mouse was given to one naive mouse. 14 days later spleens were infectious centre-assayed for latent infection. Symbols show 554 individual mice, bars show means.

c. C57BL/6 mice were infected nasally ( $10^{5}$ p.f.u. in $\left.5 \mu l\right)$ with wild-type, ORF50DEL or ORF73FS MuHVfor latent virus. Symbols show individual mice, bars show means. Mixed infections gave significantly higher titers than either component single infection.

d. Mice infected as in c were infectious centre-assayed for splenic virus after 25 days. Mixed infections gave significantly higher titers than either component single infection.

e. DNA of viruses cloned (c1-c4) from mixed infection spleens in d was PCR amplified across the ORF50 deletion site (primers p3 and p4 in Fig.1a). The PCR products were resolved by agarose gel electrophoresis and stained with ethidium-bromide. WT and 50 show wild-type and ORF50DEL input viruses. $\mathrm{Mw}=$ molecular weight markers. DNA sequencing of cloned virus PCR products confirmed identity with the wild-type.

f. DNA from the mixed infection clones in e was PCR amplified across the ORF73 frameshift site (primers p5 and p6 in Fig.1a). The PCR products were digested or not with BstEll, resolved by agarose gel electrophoresis, and stained with ethidium-bromide. WT and 73 are the wild-type and ORF73FS

569 input viruses. As in Fig.2d, as c1-c4 were cloned prior to analysis, the minor residual $0.43 \mathrm{~kb}$ band 
after incubation with BstEll digestion presumably reflected incomplete digestion rather than mutant

DNA. Sequencing of the undigested PCR products confirmed identity with the wild-type.

572

\section{Figure 7. Recombinational rescue after serial mixed infection.}

574 a. C57BL/6 mice were infected nasally ( $10^{5}$ p.f.u.) with ORF50DEL MuHV-4. 5 days later they were

575 infected nasally ( $10^{5}$ p.f.u.) with ORF73FS MuHV-4. Controls were given either just ORF50DEL or just ORF73FS. 18 days after ORF73FS infection, spleens were infectious centre-assayed for latent virus.

577 Symbols show individual mice, bars show means. The dashed line shows the detection limit. Serial 578 mixed infection yielded significantly more recoverable virus than either single infection.

Figure 8. Infection at the olfactory / respiratory border.

C57BL/6 mice were infected nasally with wild-type MuHV-4 (10 $10^{5}$ p.f.u.). 1-3 days later, nose sections were stained for viral lytic antigens with a polyclonal rabbit serum (brown), and counter-stained with haemalum (blue). $\mathrm{OE}=$ olfactory epithelium, $\mathrm{RE}=$ respiratory epithelium. Representative sections show foci of infection on the olfactory side of the olfactory / respiratory border. 
Figure 1

a deletion (M1-M4, ORF4)
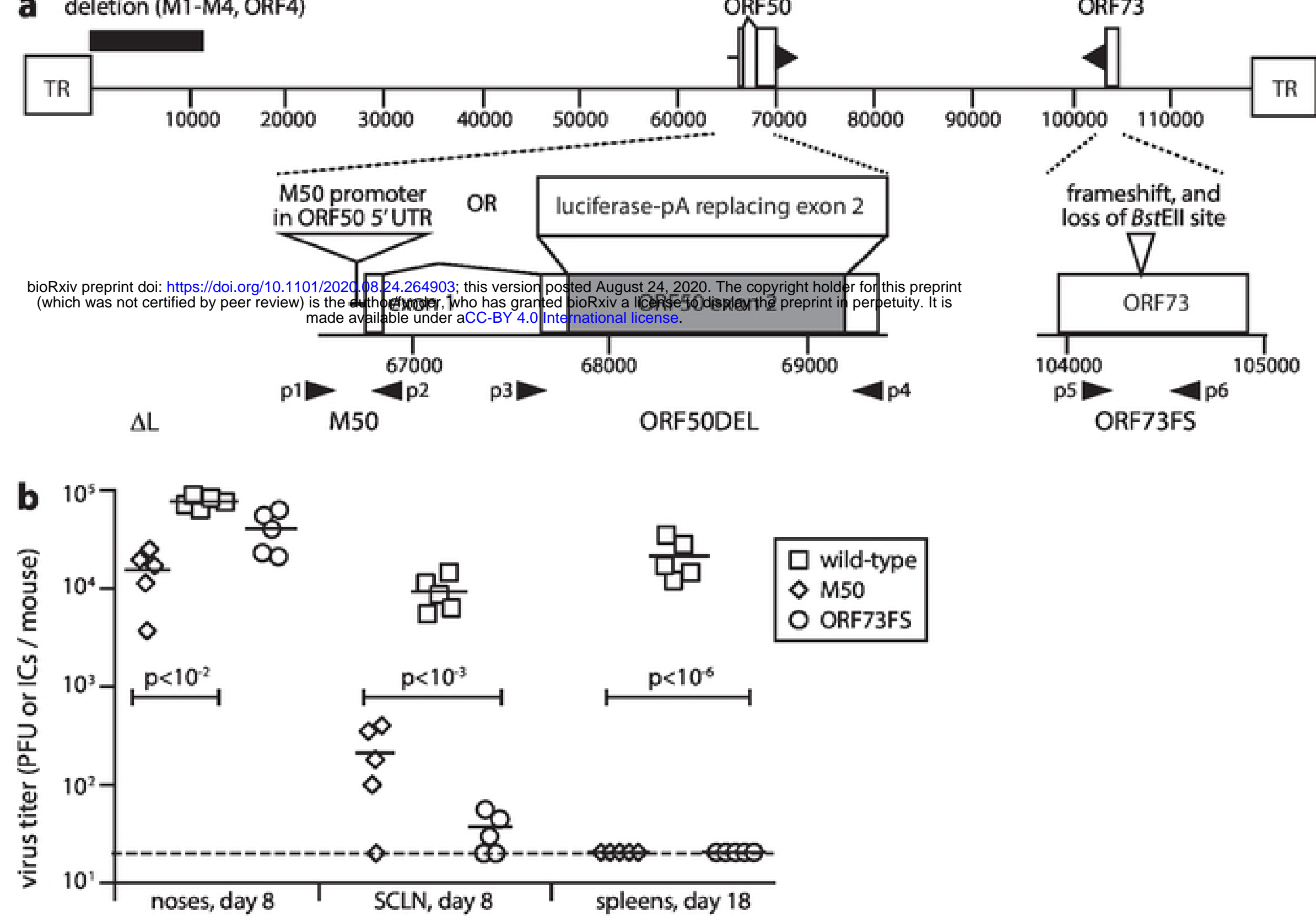


\section{Figure 2}

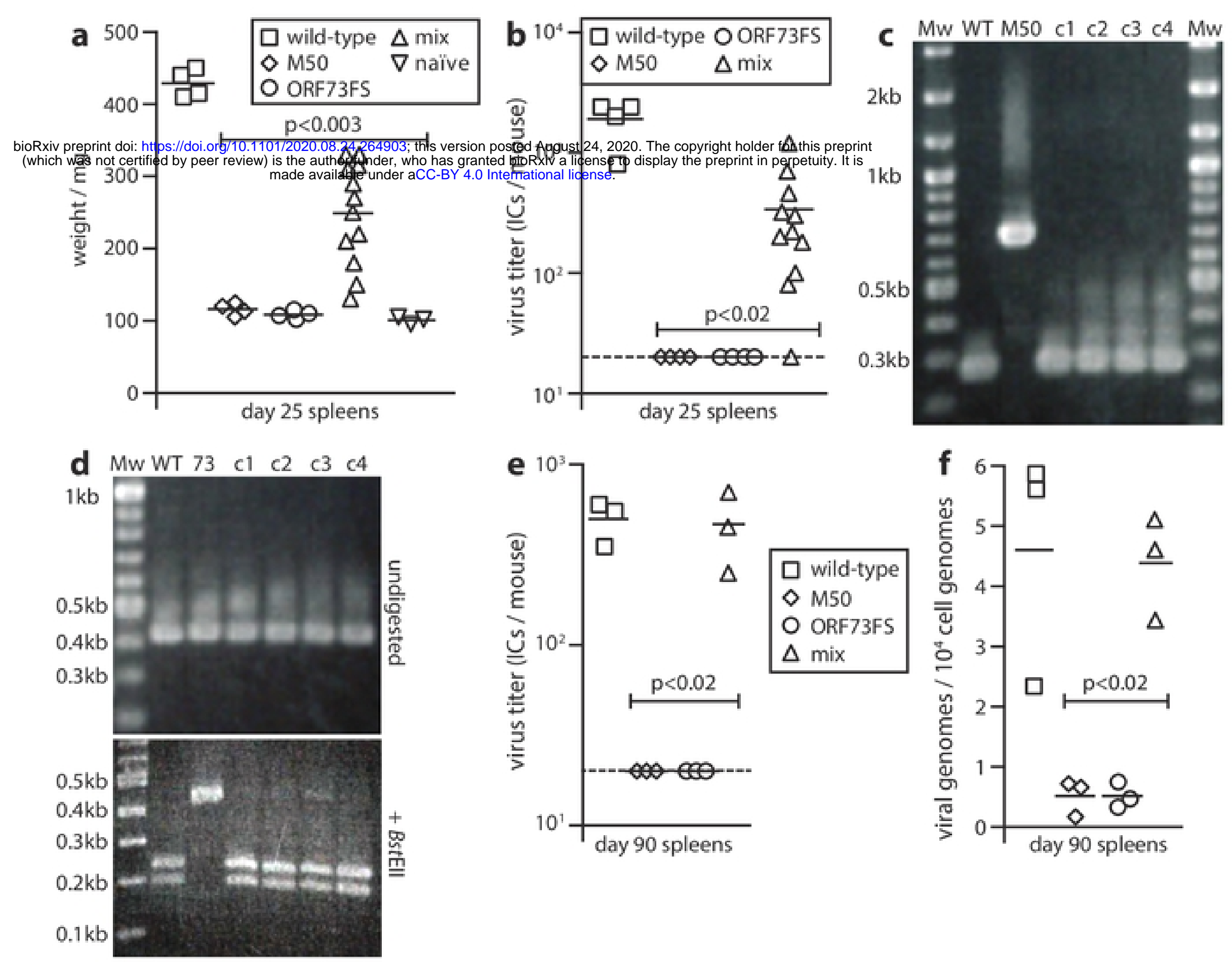




\section{Figure 3}

bioRxiv preprint doi: $h$ htps://doi.org/10.1101/2020.08.24.284903; this version posted August 24, 2020. The copyright holder for this preprint
(which was not certified by peer review) is the author/funder, who has granted bioRxiv a license to display the preprint in perpetuity. It is

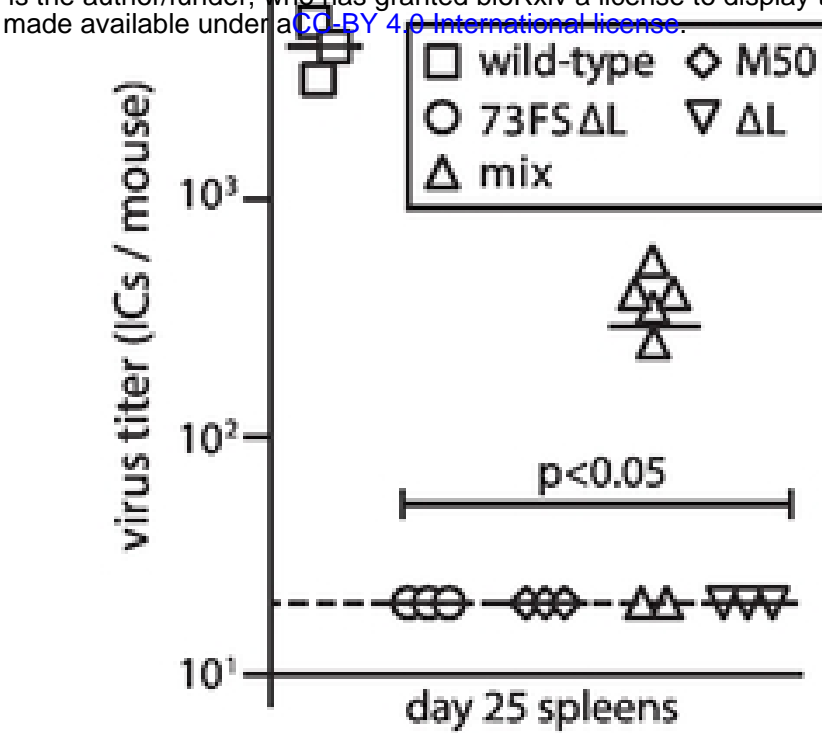


Figure 4

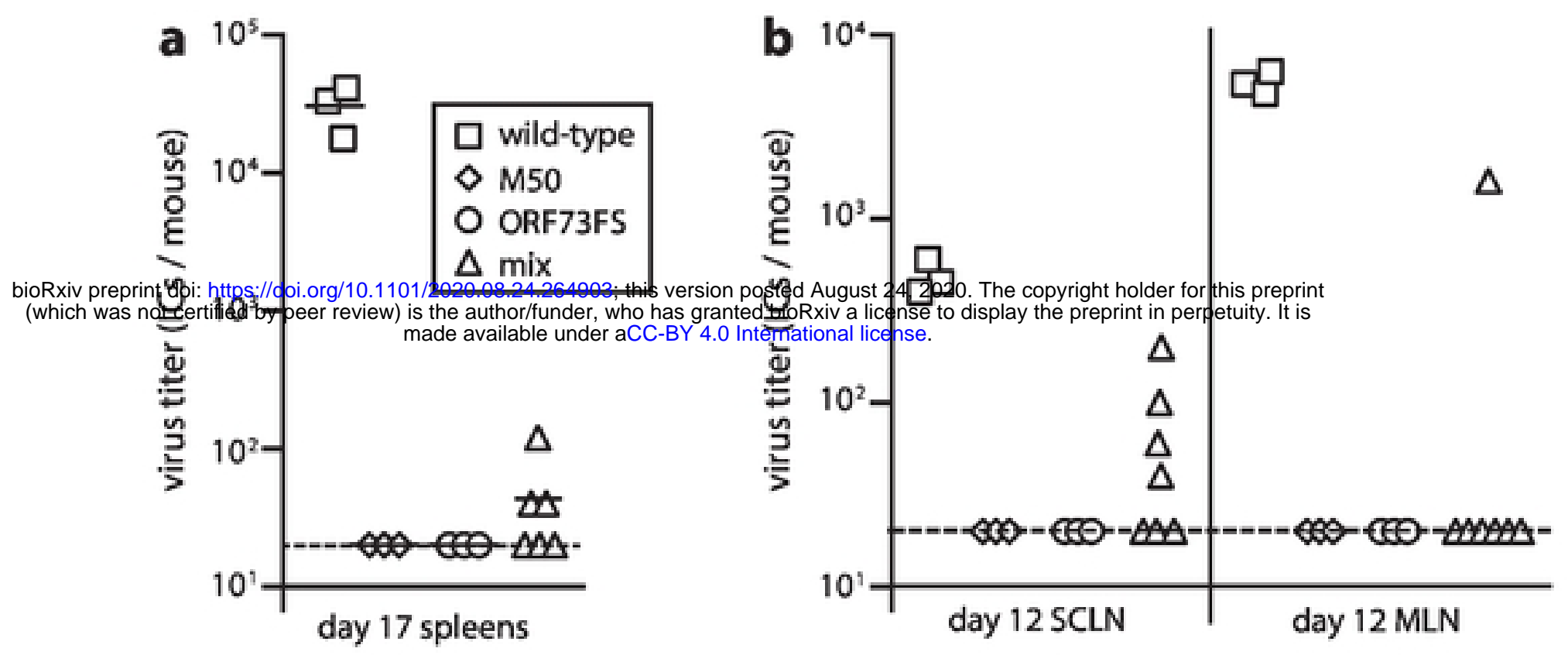


bioRx Fpief (which was hol certified by peer review) is the author/funder, who has granted bioRxiv a license to display the preprint in perpetuity. It is made available under aCC-BY 4.0 International license.
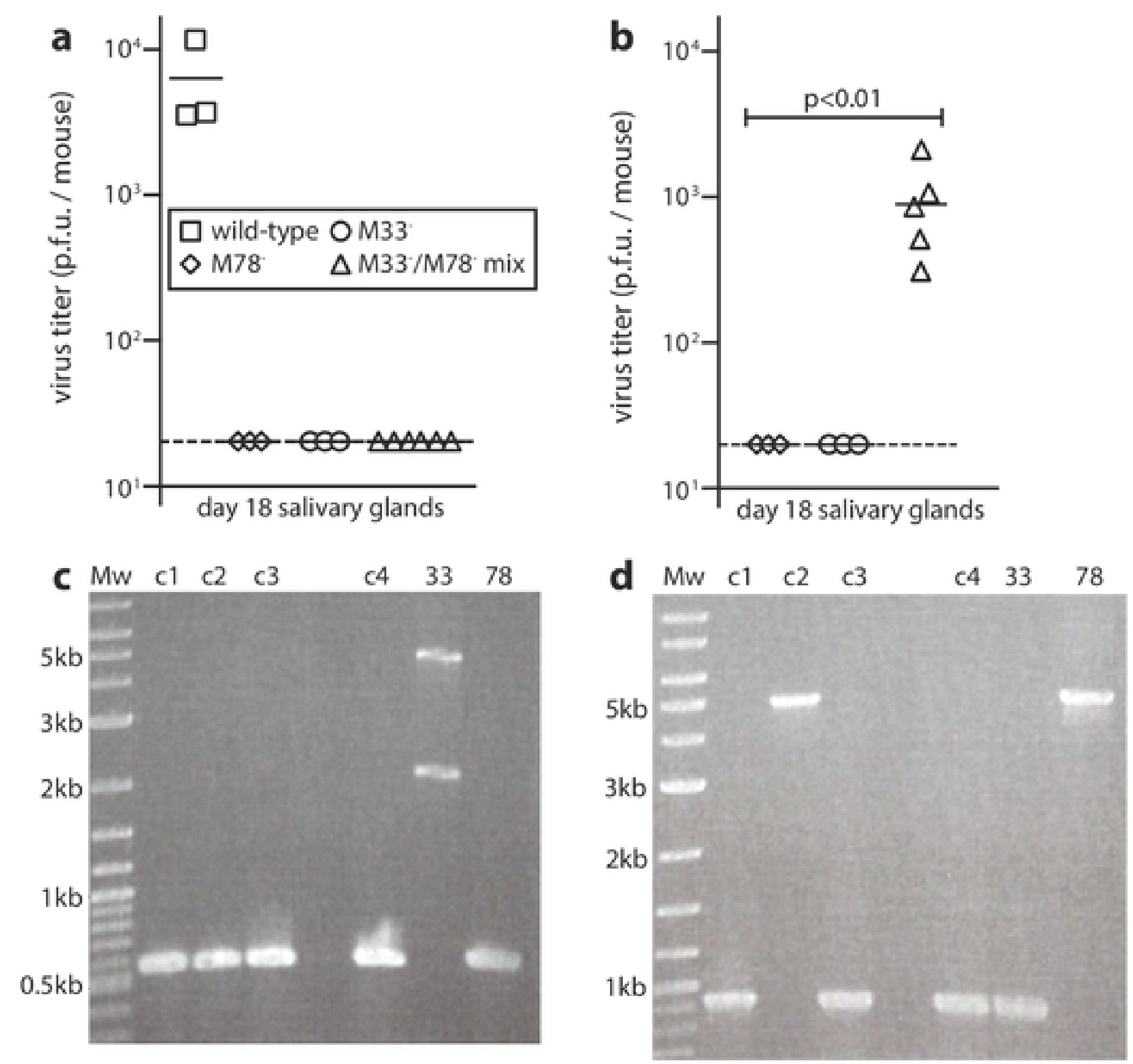


\section{Figure 6}
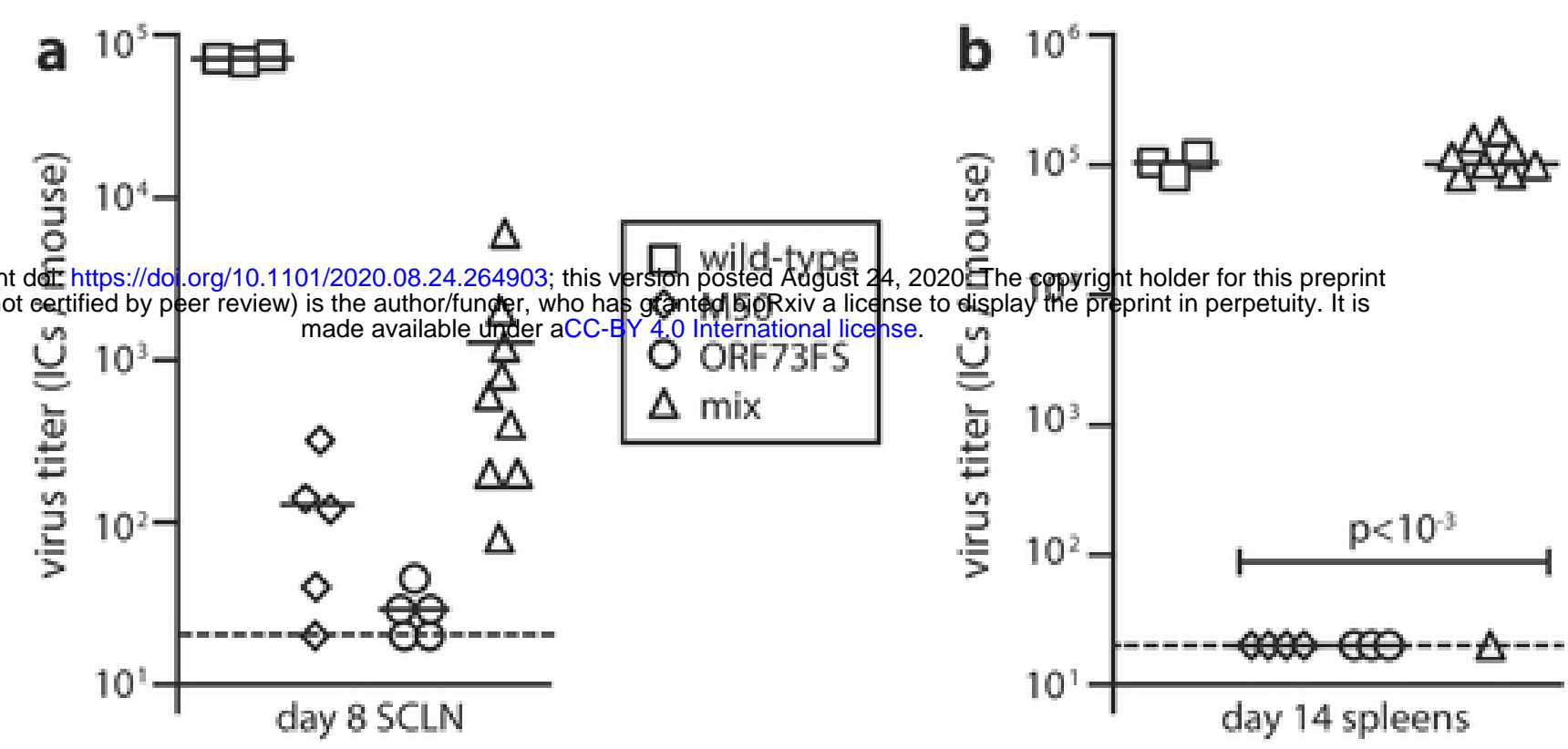

bioRxiv preprint deit $h$ ttps://do. org/10.1101/2020.08.24.264903; this version posted August 24, 2020 Ghe copyright holder for this preprint
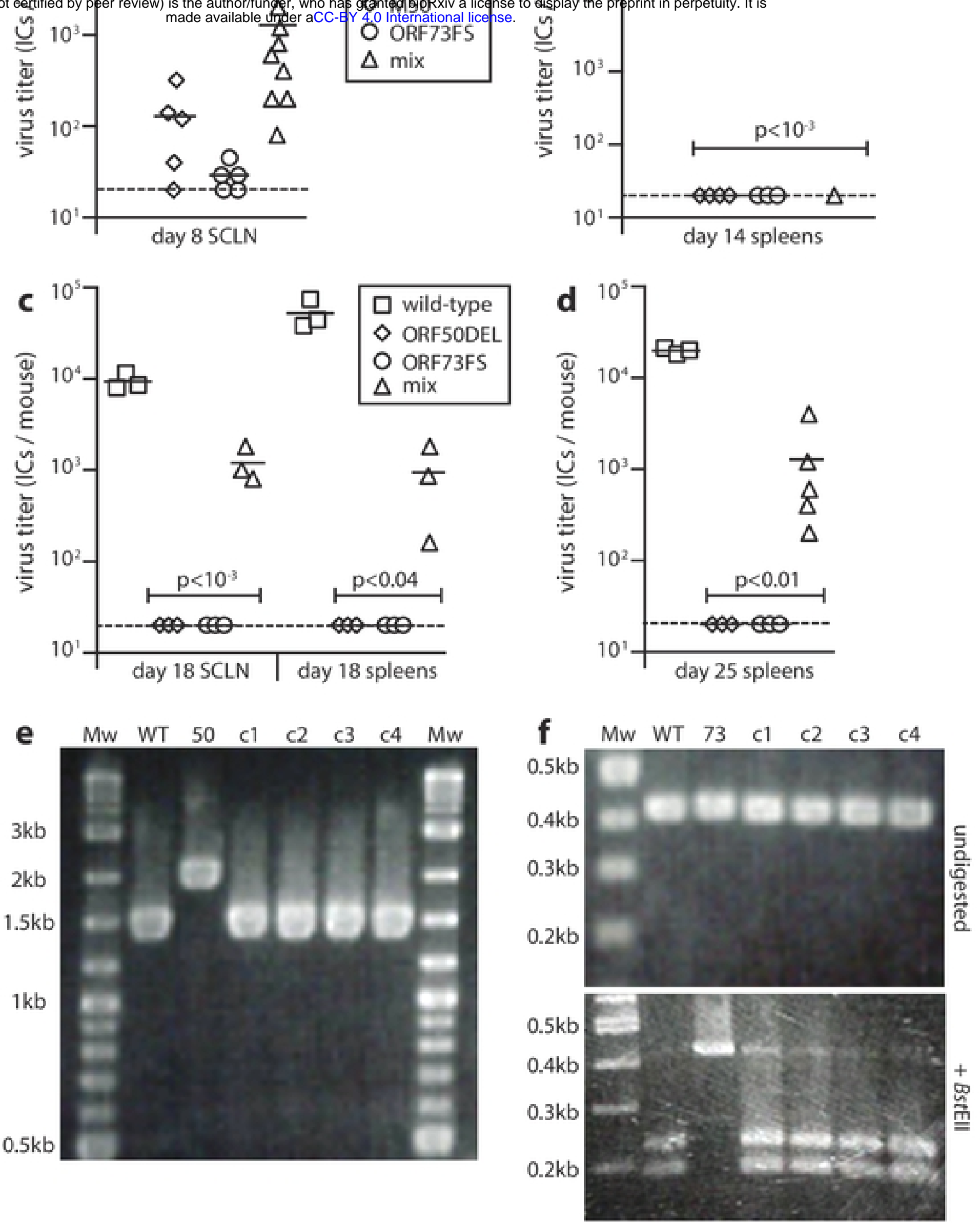


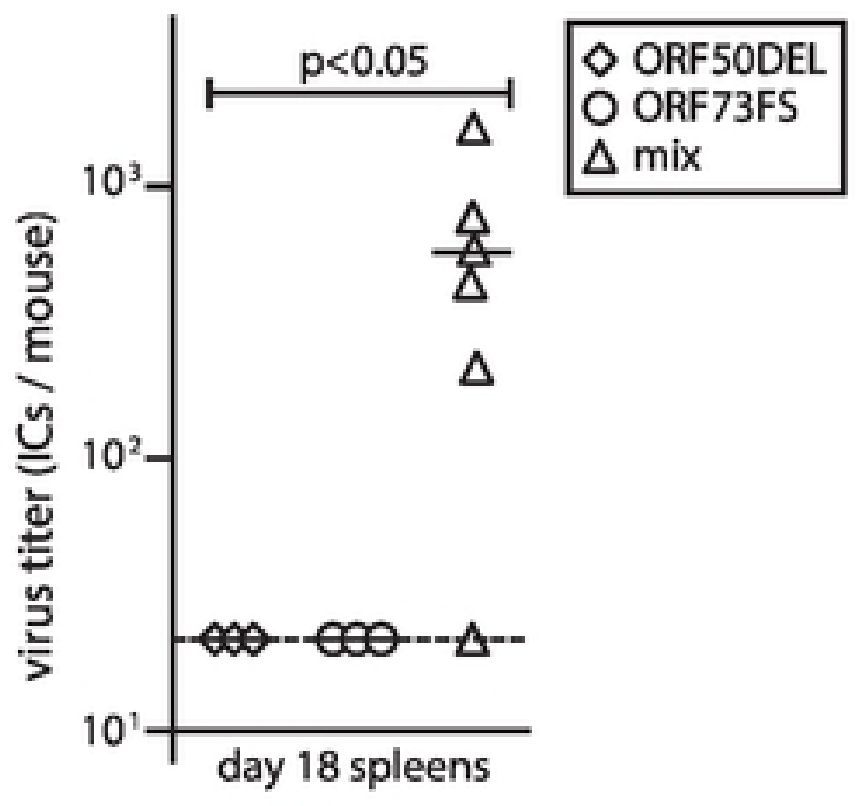




\section{Figure 8}

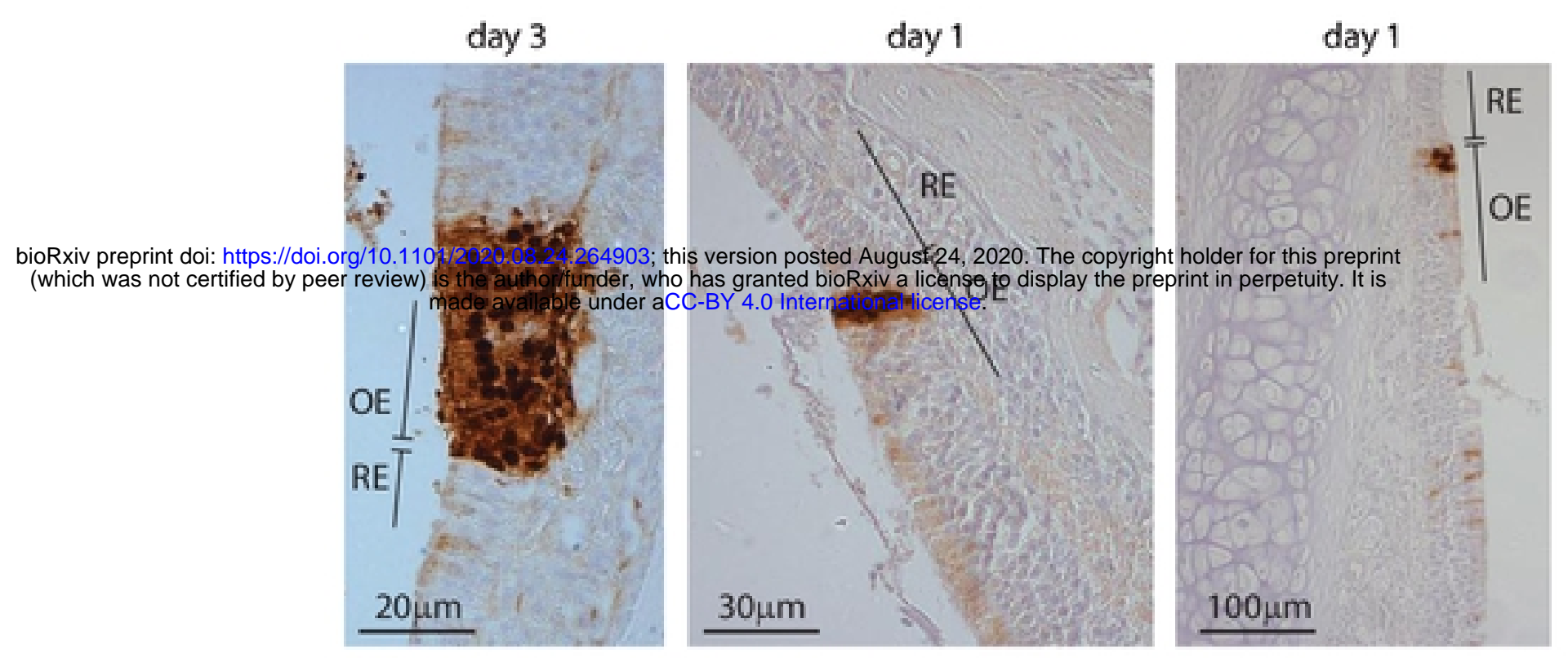

